\title{
DEVELOPMENT AND EVALUATION OF AN ART PROGRAM FOR ADOLESCENTS WITH PROFOUND EMOTIONAL, SOCIAL, INTELLECTUAL, AND ACADEMIC D YSFUNCTION
}

\section{Linda Nolan}

\section{Introduction}

Individually designed treatment programs, provided by the Florida State University Psychology Clinic, for delinquent youth committed to the A. G. Dozier School for Boys (Marianna, Florida) include several specialized components to meet their needs. The prevailing history of dependency, abuse, and deprivation demands a multi-faceted treatment approach, including an art therapy component. The art program, designed to develop an awareness of artistic process, art history, and art appreciation, attempts effective promotion of the youths' feelings of capability and accomplishment, self-worth, and value.

\section{Description of Program Environment}

The program implemented by the F.S.U. Psychology Clinic at Dozier is referred to as S.T.P., a Specialized Treatment Program. It specializes in providing intensive counseling, treatment and supervision, for incarcerated adolescent boys. Decisions for designing each individualized treatment program are made after conducting complete psychological evaluations and psycho-social assessments, family and social history, and some academic and skills assessments. Specialized components of each program include: individual psychotherapy, group psychotherapy, substance abuse education and counseling, sex education and counseling, art therapy, a variety of recreational and developmental activities, and participation in a token economy program.

A multidisciplinary approach enables specialists from the respective disciplines to better formulate an appropriate treatment plan, and utilize objective measures to assess the student's progress in achieving the targeted goals specific to each individual's needs. Students' progress is then re-evaluated at interdisciplinary team meetings, resulting in a highly flexible and comprehensive program format.

Three treatment models are used in the program: (a) a behavioral strategy, emphasizing the use of a point system in a token economy; (b) a rationale-emotive therapy which provides the theoretical base of individual and group psychotherapy; and (c) milieu therapy which includes activities in the fine arts, sports training and field trips, as major components in the over-all therapeutic milieu. Those youth committed to Dozier who evidence severe social, emotional and behavioral problems, not met in the normal training school program, are exposed to treatment models designed specifically to meet their unique needs.

\section{Specific Population}

The life experiences of this population, though diverse, consistently reveal a history of dependency, abuse, and deprivation. Their emotional, behavioral and 
and social deviances are often the result of a chaotic and often abusive environment, creating profound defects in basic psychological capacities. Characteristic dysfunction includes: inability to delay gratification of impulses, low self-esteem, lack of social skills, inadequate understanding of the motivations or consequences of behavior, lack of empathy, inappropriate attention-seeking behaviors, depression, and inadequate impulse control.

The boys vary in ages from fourteen to eighteen and have been committed on felony charges, with sentences from three months to an indefinite time period, not to extend past midnight of their nineteenth birthday. The number of students in the program may vary, but not exceed forty at any one time. They are all accepted into the STP program with profound emotional, social, intellectual and academic dysfunction. The initial goal of the program is for the student to demonstrate successful adjustment within the institutional setting. The over-all, longer-term goal is the eventual development of sufficient skills necessary for social, emotional and vocational reentry into the community at large.

\section{Program Development}

Developing an art program for a special population encompasses a wide range for possible success or failure which is "situationally-based." It is dependent on intent, implementation and expectations of those who develop the program, and those for whom the program is developed. The situation governs the format. The qualifiers within the title of my research, and descriptions of environment and population, reflect the desire to develop an art environment for a specific population, with a focus on the arts as a basis for experiencing situations which will stimulate the senses towards growth: artistic, mental, physical and emotional. To encourage the discovery and development of an intrinsic desire for increased self-motivation and self-control, separate from extrinsic reward and/or punishment motivators, is a long-term desired outcome.

Elinor Ulman believes that "art therapy legitimately covers a range of activities that at the peripheries verge on psychotherapy on one hand and on art education on the other. Art is the meeting ground of the inner and outer worlds as experienced by human individuals. Therapy aims at favorable change in personality or in living that endures beyond the therapeutic session itself" (UIman, 1980, pp. 4). Janie Rhyne believes that "Therapists who stress the humanistic orientation are more interested in exploring human potentials than they are in establishing institutions to explain and systematize the limits of human performance" (Rhyne, 1980, pp. 7). Edith Kramer stresses "unity of process and product, the integration of manual, intellectual, imaginative, and emotional faculties" (Kramer, 1986, pp. 9).

The focus of the art program is to develop this awareness of artistic processes, and to encourage a meaningful understanding of the creative thinking involved. It is designed to offer a supportive presentation of art materials and other resources, inviting participation appropriate to the youth's interest and individual developmental stage of art expression. Also accepting the adolescents' willingness to share thoughts and feelings, the environment encourages them to recognize and extend these insights beyond the studio session. The program attempts to provide meaningful, qualitative, creative art experiences for each person, with the desire that these experiences will interconnect with his environment and expand his 
horizons towards the future.

Such a program attempts to discover each youth's interests, motivations and involverinents, while allowing him to become aware of himself. The ideas, concepts and inspiration behind the creative act evolve individually, and blend with processes and media with appropriately structured direction and guidance. Using the art processes, knowledge of art history, and discerning approaches to understanding and appreciating art, a well-balanced, harmonious blend is created.

Art activities for individuals are planned using individual evaluation of student's needs, interests, and developmental stage. Proposed activities include drawing, painting, printmaking, papermaking, sculpture and other three dimensional media, ceramics, photography, fibers, and metalwork/jewelry. Art activities are made available to each resident at least four days of each week for three hour sessions, with additional time and attention provided as needed and available. Specific class schedules, make-up, and location, have changed frequently over the months, but adherence to the "Art Activities Rules" has been consistently enforced. It is based on achieving four possible points within the art program time period, and was developed to encourage frequent positive reinforcement within the behavior-modification format.

Art Points: ( 4 points total)

1 pt. = Attendance (enter room quietly and promptly)

1 pt. = Participation 1st hour (following activity rules)

1 pt. = Participation 2nd hour (follow activity rules)

1 pt. = Attendance (remain in the art area until class is dismissed)

Representative activity rules to be followed include: 1. Control and proper use of art materials. Each material will be presented and explained in-depth during class, and misuse will result in loss of points and art privileges. 2. No horseplay, profanity, teasing, or excessive silliness. 3. Participation points include following art instructions. For example: If you choose "not" to participate in a certain activity, you do not receive those points for participation.

Methods of addressing the needs and capabilities of the students within the art program were on-going, and involved the use of the following: (a) Assessment Data Sheets (name, age, sex, degree of disability noted); (b) Basic Skills Sheet (drawing, painting, cut-paper, clay); (c) Two Observation Charts (behaviors/art experiences); (d) Marlen's Sophistication-of-Body-Concept Scale (Witkin's Psychological Differentiation); (e) Eisner's Spatial Representation Scale; and (f) Schaefer-Simmern, and Lowenfeld's Child Art Stages (with ages deleted).

In addition to characteristic psychological deficiencies, these assessments revealed low developmental skills, lack of contact with art materials, little exposure to creative thinking processes, and little experience in the decisionmaking process. These assessments were not used as all-inclusive, but as a guide in determining the program's direction and eventual effectiveness. A compilation of assessment results has not yet been completed.

\section{Summary and Implications}

The design of, and the stated goals for such a program, involves a teaching 
strategy as yet still under-studied. As initiator, developer, and implementor of this particular art program, it could be considered a preliminary pilot study into the effects of an art-related teaching strategy on incarcerated youth. Working towards a synthesis of the data gathered, attempting a conceptualization of what it may imply for the future planning of art programs for this specific population, is in process. Bruner reminds us that education in general should place emphasis upon the students' skills "In handling things, seeing and imagining objects, and performing symbolic operations, particularly as they relate to the technologies that make them so powerful in their human, that is, cultural expression" (Bigge, pp. 238). Bruner recognizes the role of both extrinsic and intrinsic rewards in the promotion of learning, but sees a need to emphasize intrinsic motives and rewards in the teaching/learning process. The seven overlapping directions he suggests for general education are particularly supportive to this program: 1 . the satisfaction that is gained from quickened awareness and understanding, 2. the challenge to exercise one's full mental powers, 3 . a developing interest and involvement, 4. the satisfaction gained from one's identity with others, 5. the pleasure received from one's cognitive or intellectual mastery, 6 . one's sense of competence and accomplishment, and 7. the development of 'reciprocity," which involves a deep human need to respond to others and to operate jointly with them to achieve an objective (Bigge, pp. 246).

The arts offer these opportunities to develop an intrinsic reward system for oneself, by providing a source of continuously available knowledge made possible through problem-solving efforts involved in the creative process.

The successful continuation of such a program could provide potential directions and opportunities for future study based on the responses received to date from Dozier staff and students involved with this program. If future research could bring awareness to professionals in other fields of the positive power rehabilitation-education through the arts can possess, the possibilities are limitless for initiating programs in training schools, detention centers, and halfway houses, and more specifically, the positive connection the arts can effect between an adolescent delinquent and the world in which he must survive and function.

\section{REFERENCES}

Bigge, M. (1982). Learning Theories for Teachers, 4th Edition, Harper $\varepsilon$ Row, Publ.

Kramer, E. (1980). The unity of process and product. In Art Therapy Viewpoints, N.Y.: Schocken Books.

Rhyne, J. (1980). Divergency and growth in art therapy. In Art Therapy Viewpoints, N.Y.: Schocken Books.

UIman, E. (1980). Innovation and aberation. In Art Therapy Viewpoints, N.Y.: Shocken Books. 